\title{
Evaluation of EUV Resists For 5 nm Technology Node and Beyond
}

\author{
Zuhal Tasdemir*a , Xialong Wang ${ }^{\mathrm{a}}$, Iacopo Mochi $^{\mathrm{a}}$, Lidia van Lent-Protasova ${ }^{\mathrm{b}}$, Marieke \\ Meeuwissen $^{\mathrm{b}}$, Rolf Custers ${ }^{\mathrm{b}}$, Gijsbert Rispens ${ }^{\mathrm{b}}$, Rik Hoefnagels ${ }^{\mathrm{b}}$, Yasin Ekinci ${ }^{\mathrm{a}}$ \\ ${ }^{\text {a}}$ Laboratory for Micro- and Nanotechnology, Paul Scherrer Institute, CH-5232 Villigen PSI, \\ Switzerland \\ ${ }^{\mathrm{b}}$ ASML Netherlands B.V., De Run 6501, 5504 DR Veldhoven, The Netherlands
}

\begin{abstract}
For more than a decade, the semiconductor manufacturing industry has anticipated the introduction of Extreme Ultraviolet Lithography (EUVL) into high-volume manufacturing (HVM). The readiness of the supporting EUV resists is one of the requirements for HVM. While the industry is planning to introduce EUVL into HVM at $7 \mathrm{~nm}$ node, it is important to address the availability of the resists for future generations and in particular for the high-NA EUVL which will have the patterning capability down to $8 \mathrm{~nm}$ half-pitch. In this study we report on the performance of promising EUV resists evaluated by EUV interference lithography (EUV-IL) at the Swiss Light Source (SLS) at the Paul Scherrer Institut (PSI). We evaluated EUV resists that are being developed as candidate materials for future technology nodes and we assessed their potential for high-NA EUV lithography. Several new chemically-amplified resists (CARs) and nonCAR resists have been investigated with the aim to resolve patterns down to $10 \mathrm{~nm} \mathrm{hp}$. While, up to now, CARs performance reached down to $13 \mathrm{~nm}$ half pitch (hp) only, we report about a recent CAR that can partially resolve lines down to $11 \mathrm{~nm} \mathrm{hp}$. Moreover, some other non-CAR resists have achieved resolutions down to $10 \mathrm{~nm}$. We evaluated essential parameters, such as critical dimension (CD) and line edge roughness as a function of dose and we estimated the exposure latitude (EL). Furthermore, we report on the ultimate extendibility of CAR platform materials in manufacturing, and on novel resist platforms developed to address the challenges in the patterning at $\mathrm{hp} \leq 10 \mathrm{~nm}$.
\end{abstract}

Keywords: EUV lithography, interference lithography, aerial image, high resolution patterning, photoresist

\section{INTRODUCTION}

As industry has been preparing to make the switch from DUV to EUV lithography, several challenges still remain to be overcome. Among them, there is the critical need for highly efficient, low linewidth roughness resists that can support high-resolution patterning for the future technology nodes. In this work, we report the findings of our EUV resist testing program which we have conducted in the first three quarters of this year as ASML is and focused on materials aiming to enable patterning of sub $8 \mathrm{~nm}$ features [1-3]. Within the framework of this study, we evaluated EUV resists candidates under development for future technology nodes and in particular we assessed the readiness of EUV materials for highNA EUV lithography. Several novel chemically-amplified resists (CARs) and non-CAR resists have been investigated with the aim to resolve patterns down to $10 \mathrm{~nm} \mathrm{hp}$.

*zuhal.tasdemir@psi.ch; phone +410563105807

International Conference on Extreme Ultraviolet Lithography 2018, edited by Kurt G. Ronse, Eric Hendrickx, Patrick P. Naulleau, Paolo A. Gargini, Toshiro Itani, Proc. of SPIE Vol. 10809,

108090L · @ 2018 SPIE · CCC code: 0277-786X/18/\$18 · doi: 10.1117/12.2502688 
We analyzed and reported essential parameters, such as critical dimension (CD) and line edge roughness as a function of dose, and we estimated the exposure latitude (EL) on the basis of the dose range that we used. This work will shed light on the ultimate extendibility of CAR platform materials in manufacturing, and on novel resist platforms developed to point out the challenges in the patterning below $10 \mathrm{~nm}$ hp.

EUV resist materials are a key component of the EUV lithography process and have a major impact on its throughput and yield. At Paul Scherrer Institute (PSI), we operate an interference lithography (IL) tool that is the ideal platform to perform early research on these materials [4-10]. With EUV-IL, it is possible to perform an assessment of the performance of the most advanced resist material by probing their maximum resolution limit. Our experimental setup consists in a mask with diffraction gratings, illuminated by a spatially coherent beam with a wavelength of $13.5 \mathrm{~nm}$. The first order diffraction beams interfere and create a periodic aerial image on the surface of a wafer coated with the resist under test (see Fig. 1). The pattern of line/spaces is obtained by exposing two gratings with the equal period leading to sinusoidal aerial image [8]. The grating pairs are arranged in such a way that only the first order diffraction beams overlap and create the interference pattern. EUV-IL proved to be a fast and a powerful method to print both line/spaces and contact-holes patterns to help the early-stage development of EUV resist platforms for the HVM phase.

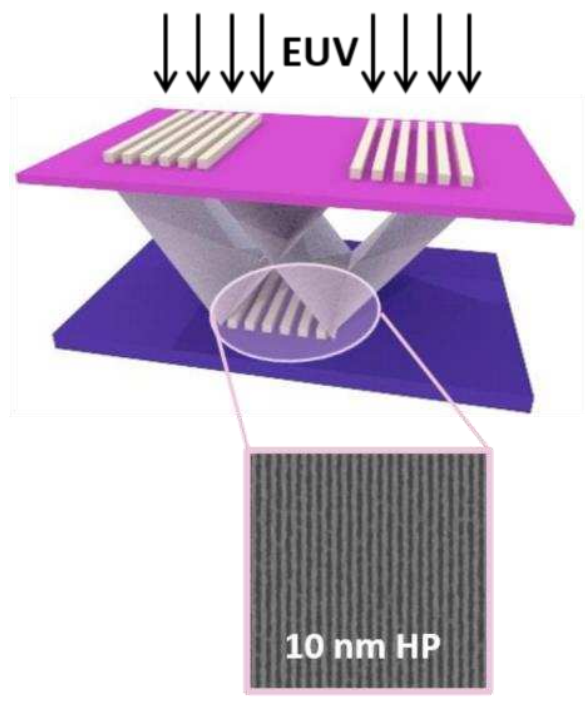

Figure 1. The scheme of the interference lithography setup that we use at PSI. A specific diffraction grating mask is illuminated with coherent EUV light and the interference pattern generated by the interaction of the $1^{\text {st }}$ order beams exposes a resist-coated wafer.

One of the advantages of using interference lithography for EUV resist testing is the possibility of creating periodic patterns with high resolution. The theoretical resolution limit for the setup we operate is $3.5 \mathrm{~nm}$ and so far, we managed to demonstrate patterning of lines with $7 \mathrm{~nm} \mathrm{hp}$. Another advantage is the lack of dose, outgassing or contamination limitations. In summary, EUV-IL is a low-cost technique, easily accessible to resist vendors for advanced material testing. The practical limit of our achievable resolution depends on the resist and on the quality of the diffraction gratings' masks. To mitigate the impact of the grating quality on the resolution, we developed a simple yet efficient technique to produce better masks.

The gratings consisting of HSQ lines are patterned by e-beam lithography on $100 \mathrm{~nm}$-thick Silicon Nitride $\left(\mathrm{Si}_{3} \mathrm{~N}_{4}\right)$ membranes as shown in Fig. 2(a). Then, hydrogen silsesquioxane (HSQ) is spin-coated and diffraction gratings are written by e-beam lithography tool, Vistec EBPG 5000Plus, (Fig. 2(b)), this step is followed by PMMA coating and again e-beam lithography of the photon-stop layer definition, as shown in Fig. 2(c). Chromium and gold metal layers are coated and put in acetone for the lift-off for the seed layer outside of the grating areas. Finally, nickel is coated by electroplating (Fig.2 (d)).

For the resist screening tests, we use transmission masks with several grating pairs providing different half-pitches. The aerial image is a sinusoidal pattern and the contrast is pitch independent. Since the inference pattern is z-invariant, there is no depth-of-focus issues. In a typical experiment, we perform a series of exposure with different doses, providing CD and LWR versus dose and exposure latitude. 


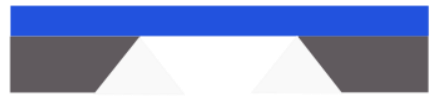

(a)

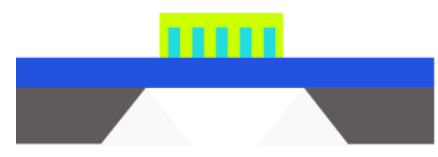

(c)

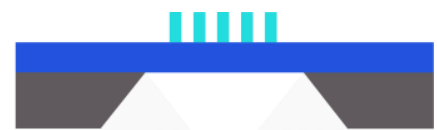

(b)

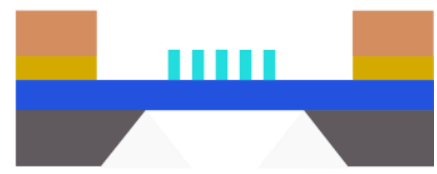

(d)

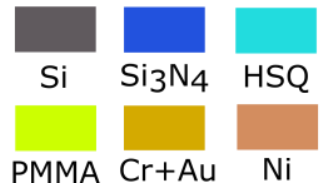

Figure 2. Key steps of the process flow designed for the production of highly efficient diffraction mask gratings.

\section{EXPERIMENTS AND RESULTS}

EUV-IL exposures are performed on $100 \mathrm{~mm}$ silicon wafers with a film thickness of ranging from $20 \mathrm{~nm}$ to $25 \mathrm{~nm}$. After the wafer development, the resulting line/space patterns are inspected with a scanning electron microscope (SEM) with an acceleration voltage of $1 \mathrm{kV}$ and a working distance of $3.0 \mathrm{~mm}$, (Supra V55, Zeiss, Germany). Afterwards, metrology analysis carried out using the commercial software SUMMIT (Lithometrix, USA).

The highlights of our resist screening program of this year are shown in Fig. 3. The best inorganic resist we tested resolved from hp $13 \mathrm{~nm}$ down to hp $10 \mathrm{~nm}$ with a dose of around $70 \mathrm{~mJ} / \mathrm{cm}^{2}$. The best chemically amplified resist (CAR)

resolved from hp $13 \mathrm{~nm}$ down to $12 \mathrm{~nm}$ with a dose value of $55 \mathrm{~mJ} / \mathrm{cm}^{2}$ and $11 \mathrm{~nm} \mathrm{hp}$ is observed to be on the wafer at the similar dose value however with some defects such as necking as seen in the lower row of Fig. 3. 


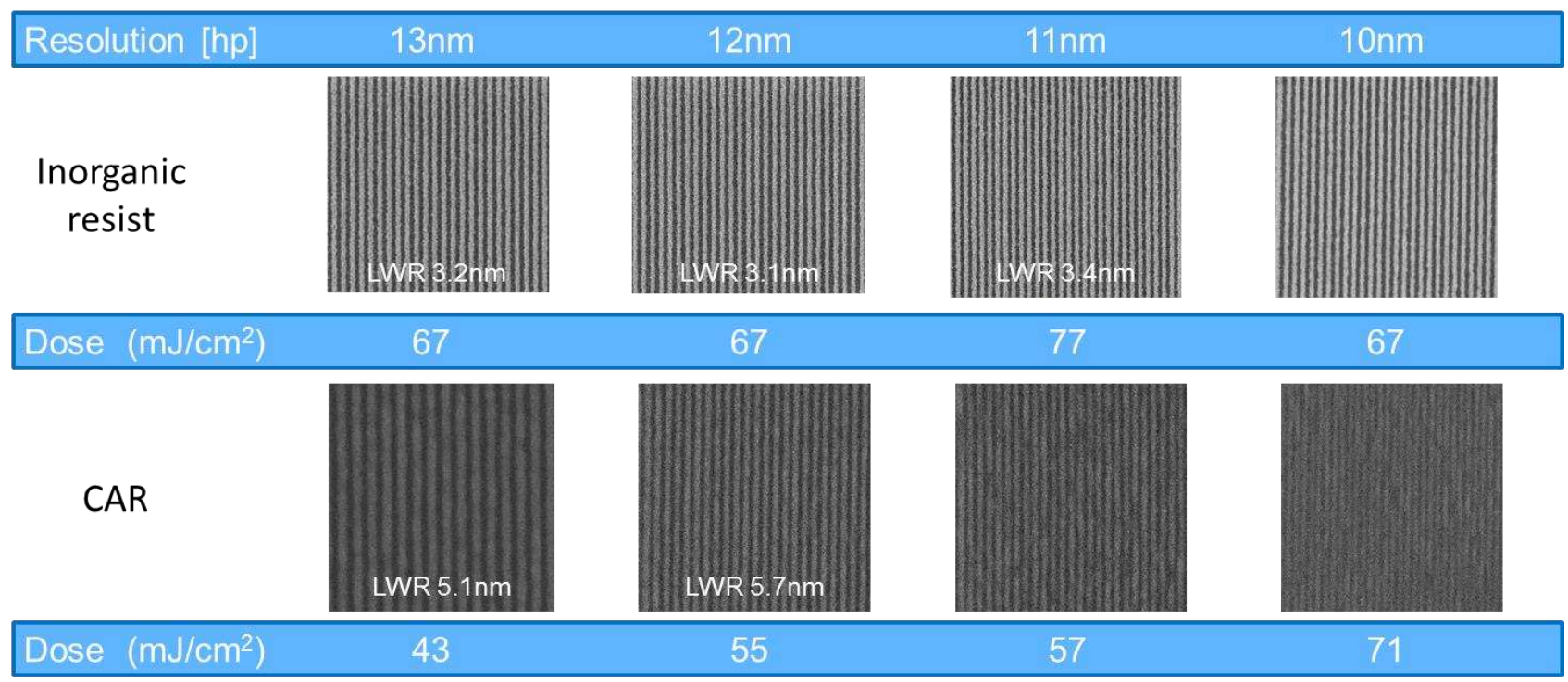

Figure 3. Highlights of the Resist Screening Program- 2018: best performing high resolution EUV resists exposed on EUV-IL.

We also highlighted the best resolution obtained in the first three quarters of this year for each resist type as shown in Figure 4. Molecular resist has resolved down to $13 \mathrm{~nm} \mathrm{hp}$ with a dose of around $33 \mathrm{~mJ} / \mathrm{cm}^{2}$. Inorganic resist went down to $11 \mathrm{~nm} \mathrm{hp}$ with a dose of $65 \mathrm{~mJ} / \mathrm{cm}^{2}$, CAR resolved down to $\mathrm{hp} 13 \mathrm{~nm}$ but at a higher dose: $98 \mathrm{~mJ} / \mathrm{cm}^{2}$. Metalcontaining CAR resist resolved down to $14 \mathrm{~nm}$ hp with much lower dose $\left(54 \mathrm{~mJ} / \mathrm{cm}^{2}\right)$ thanks to its higher EUV absorption.

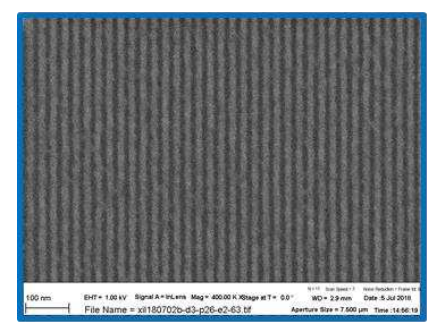

Molecular Resist

$13 \mathrm{~nm} \mathrm{HP}$

$\sim 33 \mathrm{~mJ} / \mathrm{cm}^{2}$

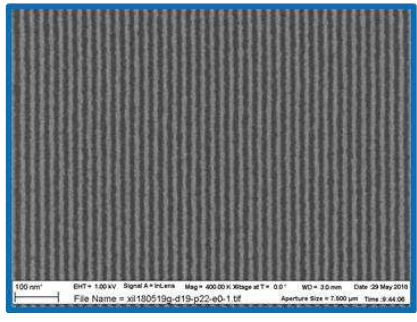

Inorganic Resist

$11 \mathrm{~nm} \mathrm{HP}$

$\sim 65 \mathrm{~mJ} / \mathrm{cm}^{2}$

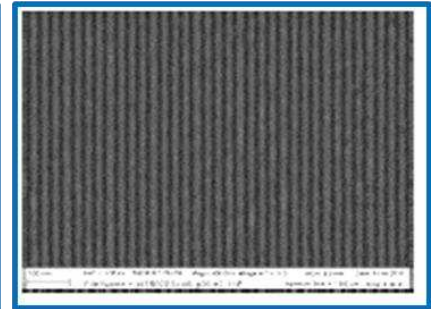

CAR

$13 \mathrm{~nm} \mathrm{HP}$

$\sim 98 \mathrm{~mJ} / \mathrm{cm}^{2}$

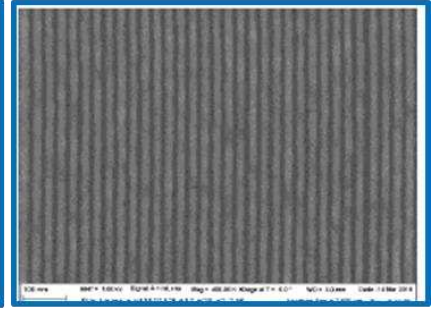

CAR-metal

$14 \mathrm{~nm} \mathrm{HP}$

$\sim 54 \mathrm{~mJ} / \mathrm{cm}^{2}$

Figure 4. Selected results of resist screening program in 2018 (Q1-Q3). SEM images of the maximum achieved resolution and dose for different resist platforms.

During the last quarter of last year, we also obtained some improved results from CAR. We have shown resolution down to $11 \mathrm{~nm} \mathrm{hp}$ with a dose of $57 \mathrm{~mJ} / \mathrm{cm}^{2}$. SEM images of line/space patterns ranging from $16 \mathrm{~nm}$ to $11 \mathrm{~nm}$ hp are shown in Fig. 5. 


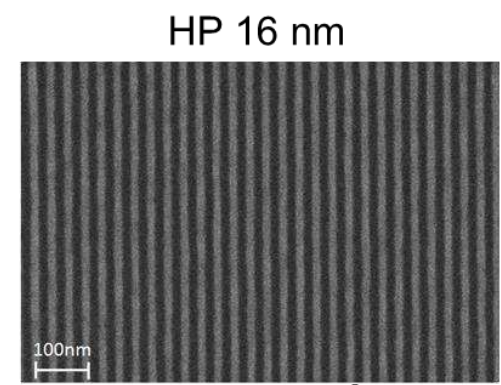

$68.8 \mathrm{~mJ} / \mathrm{cm}^{2}$

HP $13 \mathrm{~nm}$

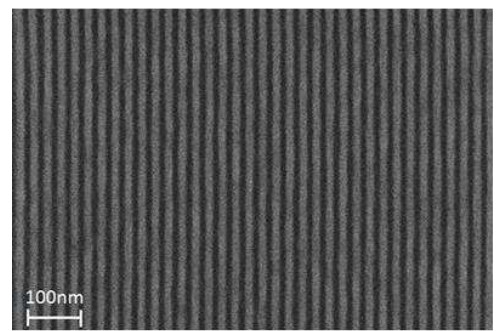

$52.8 \mathrm{~mJ} / \mathrm{cm}^{2}$
$\mathrm{HP} 15 \mathrm{~nm}$

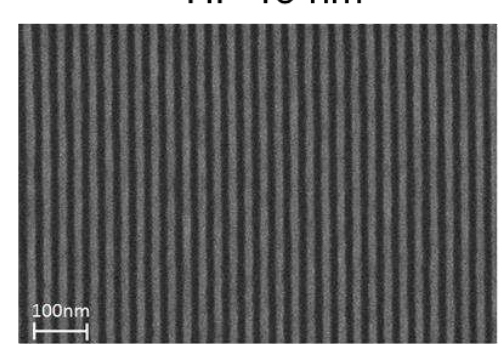

$64.6 \mathrm{~mJ} / \mathrm{cm}^{2}$

HP $12 \mathrm{~nm}$

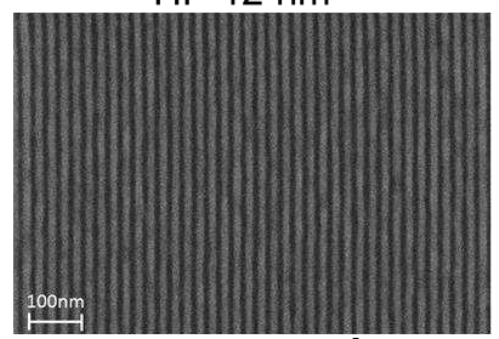

$57.6 \mathrm{~mJ} / \mathrm{cm}^{2}$

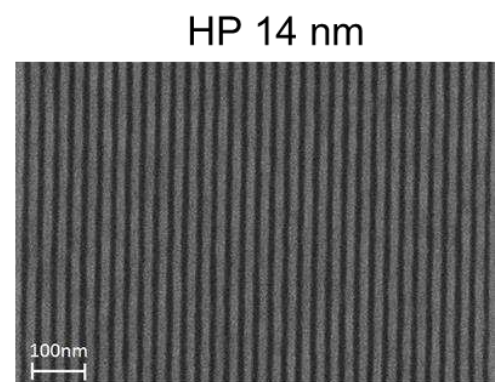

$53.0 \mathrm{~mJ} / \mathrm{cm}^{2}$

HP $11 \mathrm{~nm}$

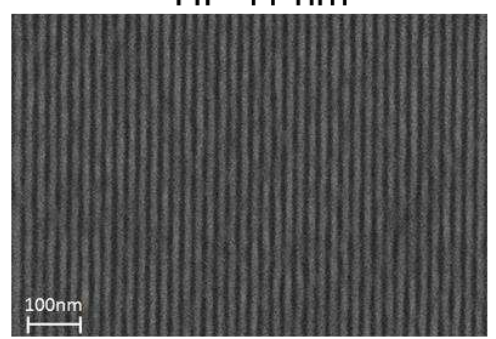

$57.0 \mathrm{~mJ} / \mathrm{cm}^{2}$

Figure 5. High-resolution CAR: down to $11 \mathrm{~nm}$ hp.

We evaluated three different molecular resists, focusing on their performance at $16 \mathrm{~nm}$ hp and below. In Fig. 6 , on the left-hand side, line/space SEM pictures are shown as the dose increases and the plots on the right-hand side show the corresponding CD and LWR vs dose. Exposure latitude of the resist is calculated based on the dose range marked in green in those SEM images. Resist thickness of 23 and $21 \mathrm{~nm}$ is used for these tests. It is clear from these pictures that all of the resists tested in this set show patterning at $16 \mathrm{~nm}$ hp with very high exposure latitudes, above $20 \%$.

The patterning results obtained at $13 \mathrm{~nm} \mathrm{hp}$ with molecular resists are shown in Fig. 7. Resolved LS patterns with a dose range of $30-50 \mathrm{~mJ} / \mathrm{cm}^{2}$, with the LWR values around $7 \mathrm{~nm}$ (see Figure 7) were obtained. The quality of the lines is not very satisfying due to high LWR values, but it is promising in terms of dose sensitivity.

At hp $12 \mathrm{~nm}$ we observe the behavior shown in Fig. 8. Although the quality of LS patterns is low due to bridging defects and also high level of LWR values, the current status of hp $12 \mathrm{~nm}$ seems promising comparing to hp $13 \mathrm{~nm}$ as seen in figure 7 . 

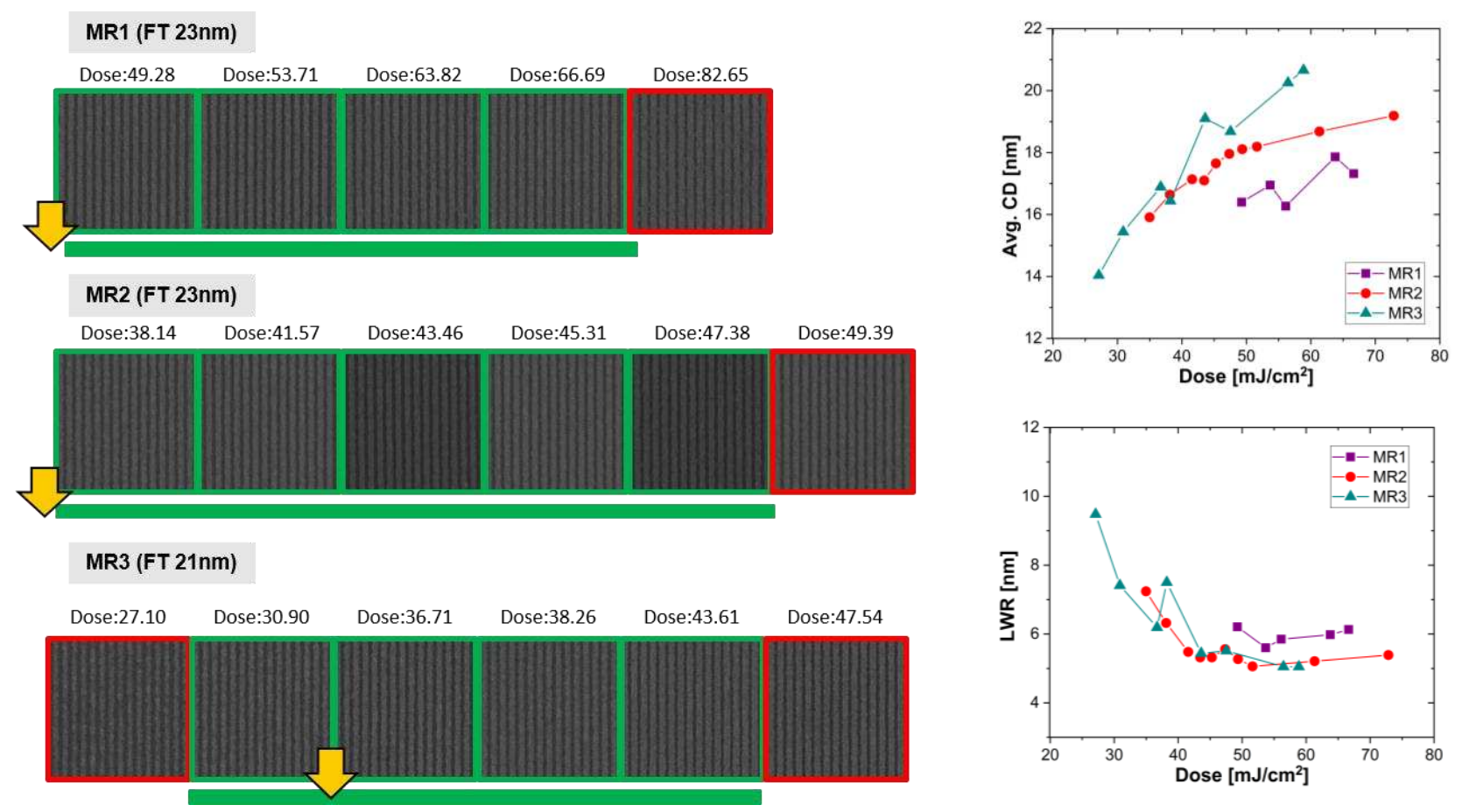

Figure 6. Through-dose SEM images, CD and LWR curves at hp $16 \mathrm{~nm}$ for Molecular Resists with three different formulations.
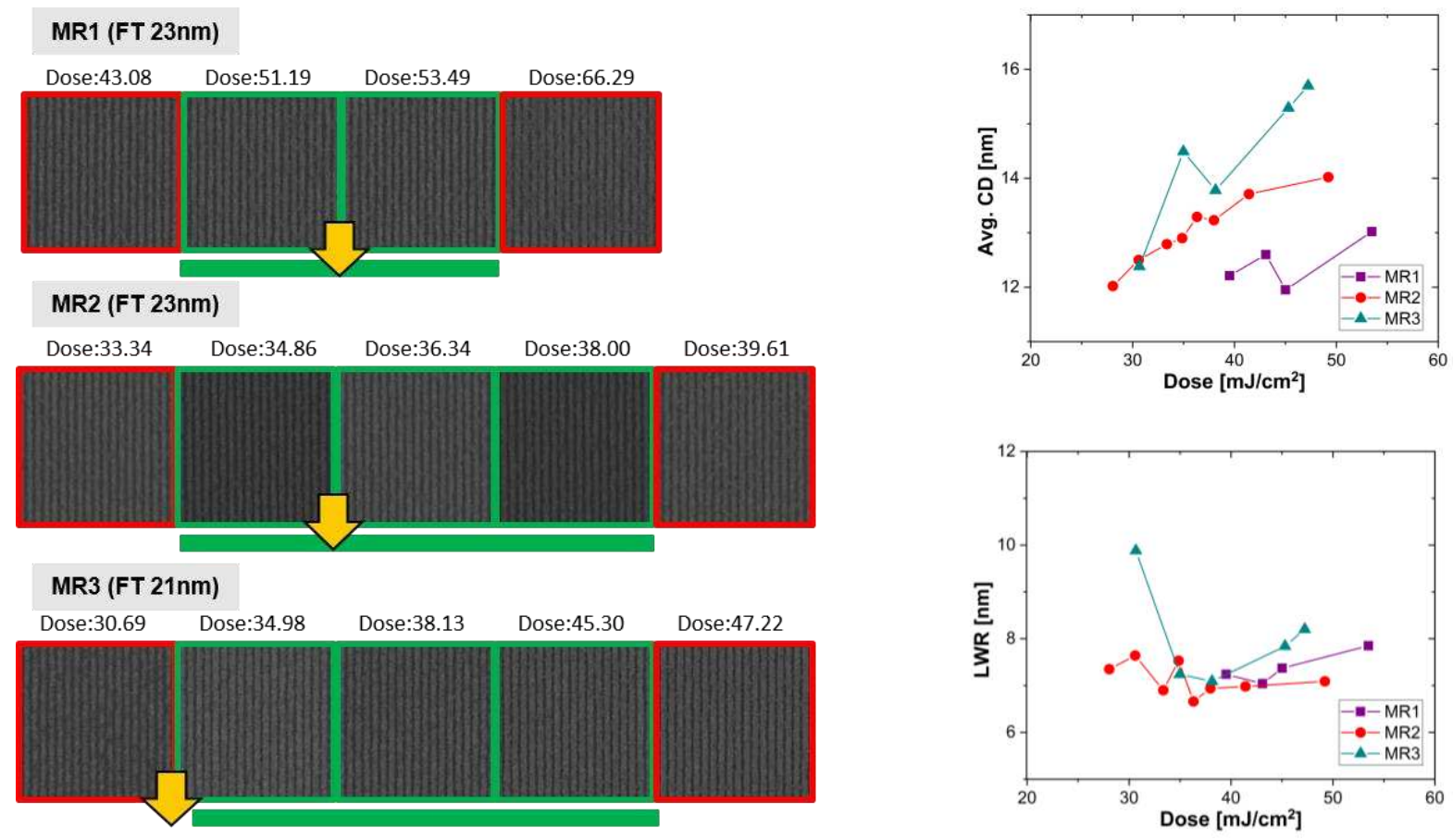

Figure 7. Through-dose SEM images, CD and LWR curves at hp $13 \mathrm{~nm}$ for Molecular Resists with three different formulations. 

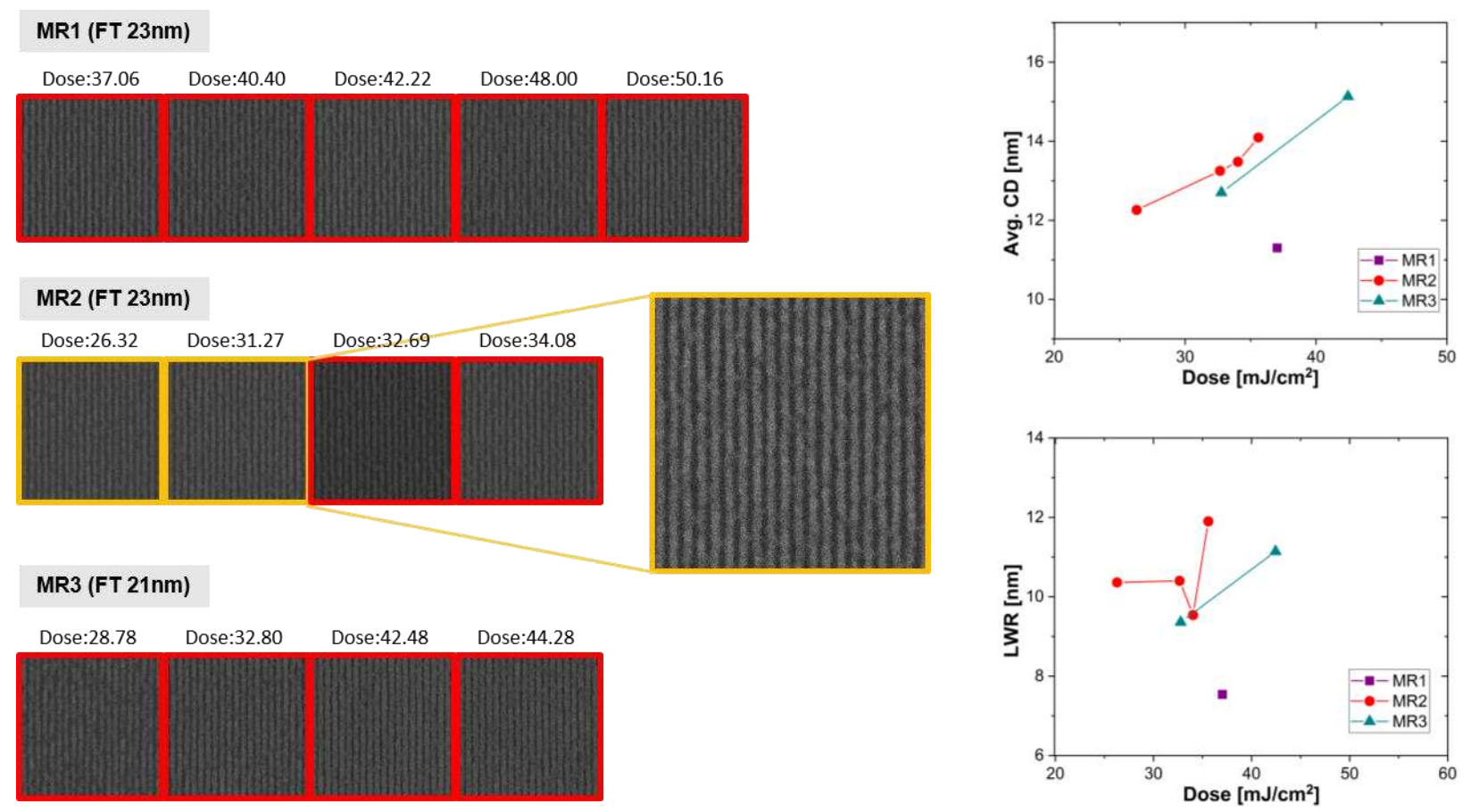

Figure 8. Molecular Resists for hp $12 \mathrm{~nm}$.

Within the framework of our global resist screening program, we also tested different development rinse materials. One of the biggest issues in high resolution patterning is pattern collapse. One of the methods to mitigate the pattern collapse is to use different development rinse materials at high resolutions. We tested four different rinse materials results, one of them being the reference with well characterized performance. We used a standard CAR resist with a film thickness of $25 \mathrm{~nm}$. We analyzed the results for both hp $16 \mathrm{~nm}$ and hp $13 \mathrm{~nm}$, (see Figure 9 and Figure 10 respectively). At hp $16 \mathrm{~nm}$, we see a similar performance for all four rinse materials at this level, with wide exposure latitude. However, in terms of CD and LWR vs. dose we observed that Rinse 1 performs slightly better than rest (Figure 9).
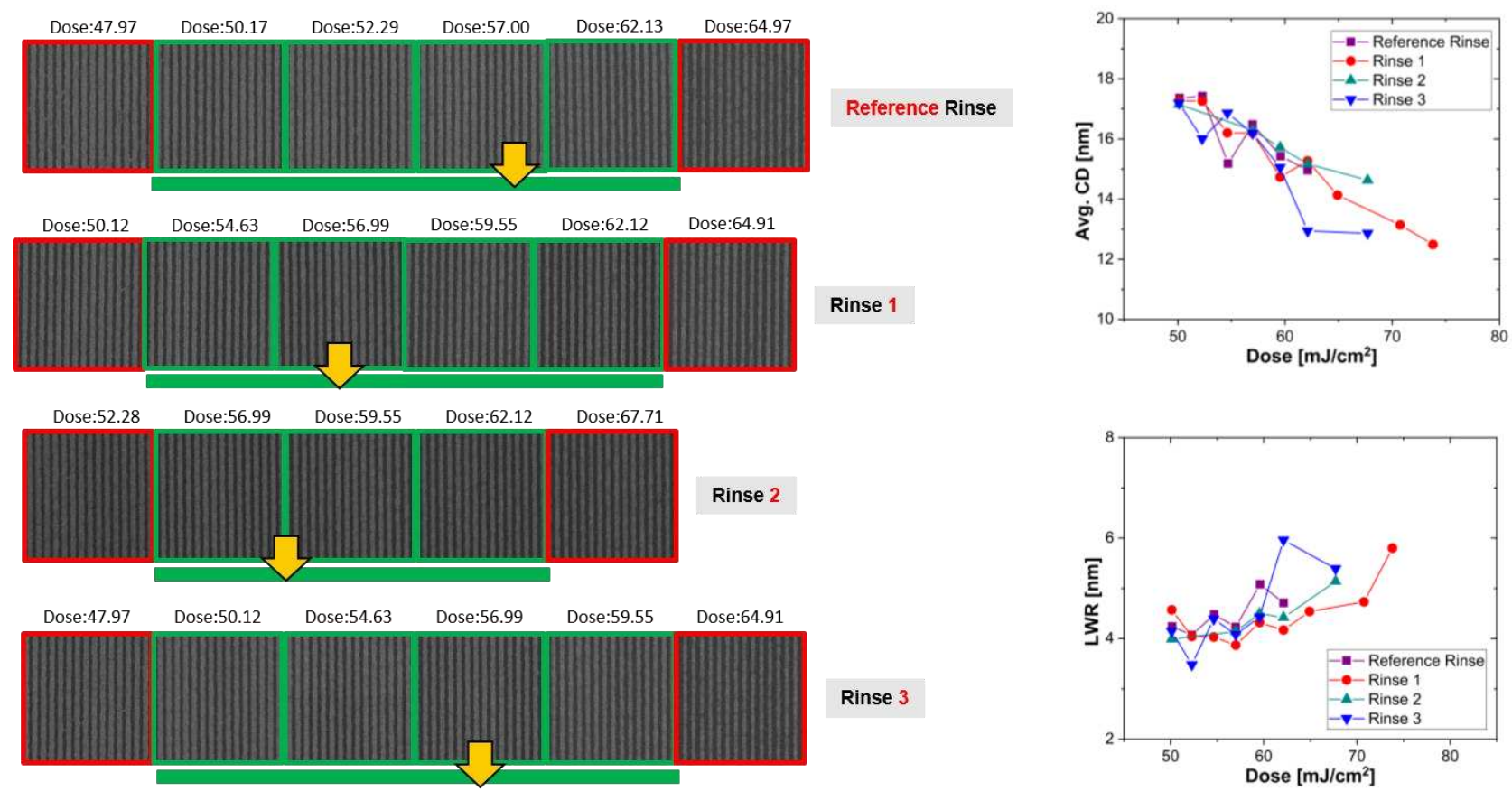

Figure 9. Different Development Rinses for hp $16 \mathrm{~nm}$. 
Using the same set of development rinses, but for hp $13 \mathrm{~nm}$, we only see decent LS patterns with the use of Rinse 1 material, (see Figure 10). From the close-up SEM picture of Rinse 1 material, we could see that the lines are free from pattern collapse, bridging or necking which is not the case for other rinse materials 2, 3 and 4 .

We have also tested some other resist platforms, such as metal containing CAR resists as shown in Fig. 11. On that graph, the performance of four different CAR- metal resists in terms of dose to size at hp 16 and $\mathrm{hp} 14 \mathrm{~nm}$ and also the corresponding LWR values is reported. CAR-metal 2 and CAR-metal 3 perform better than the rest with a dose value lower than $50 \mathrm{~mJ} / \mathrm{cm}^{2}$ and LWR values of $6-7 \mathrm{~nm}$.
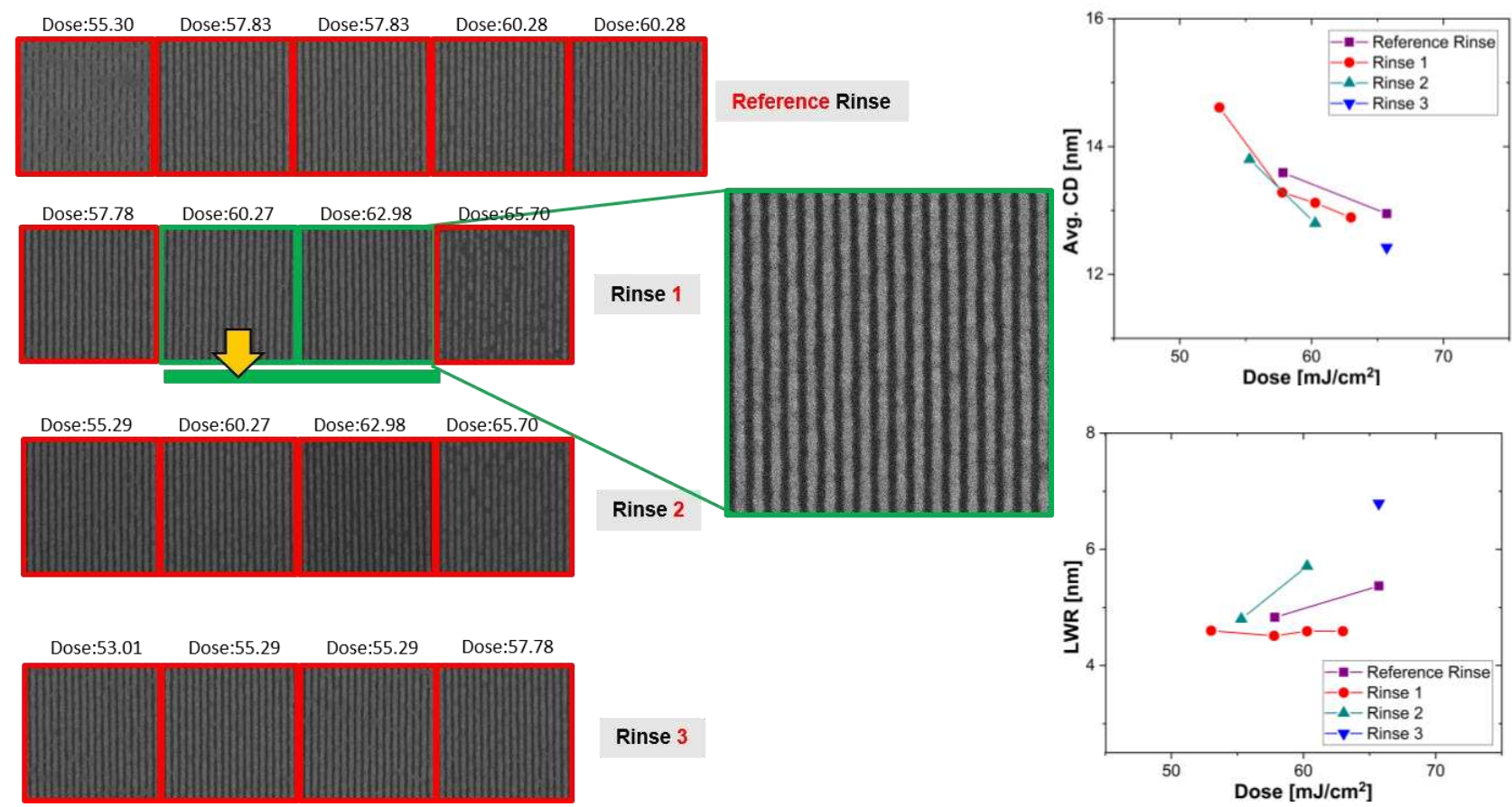

Rinse 3

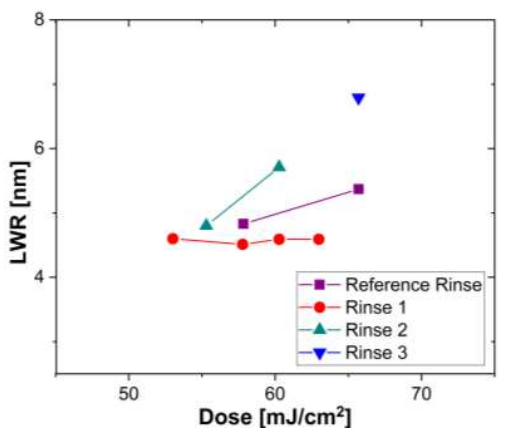

Figure 10. Comparison of the performance of a CAR with different development Rinses for hp $13 \mathrm{~nm}$.

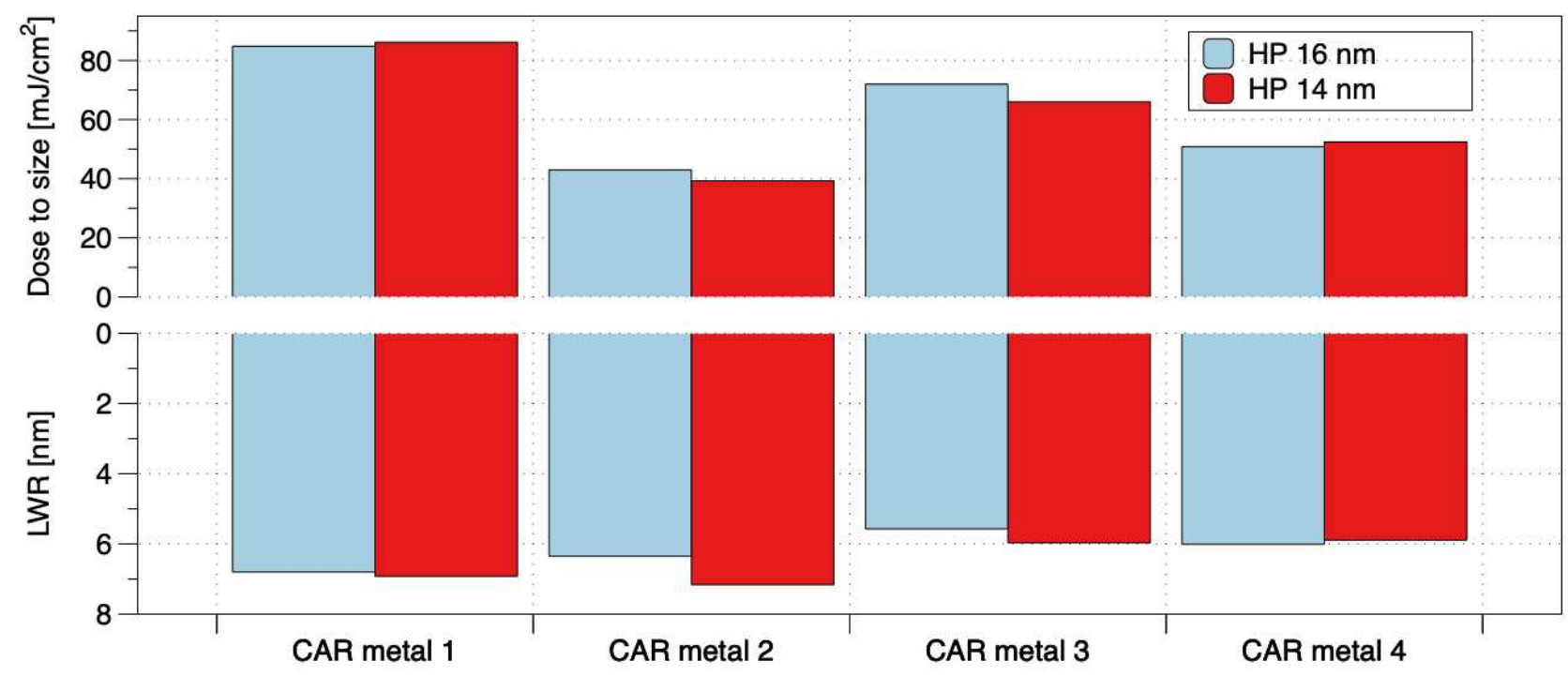

Figure 11. Overview of the metal-containing CARs for hp $16 \mathrm{~nm}$ and hp $14 \mathrm{~nm}$. 
We have also tested many different CAR resists during these three quarters, in total eight different resist types focusing on hp 16 and hp $13 \mathrm{~nm}$. Among these materials, CAR 7 and CAR 8 outperform the others with a dose to size between $50-100 \mathrm{~mJ} / \mathrm{cm}^{2}$ and with LWR values less than $5 \mathrm{~nm}$ for hp $16 \mathrm{~nm}$, and $7 \mathrm{~nm}$ for hp $13 \mathrm{~nm}$.

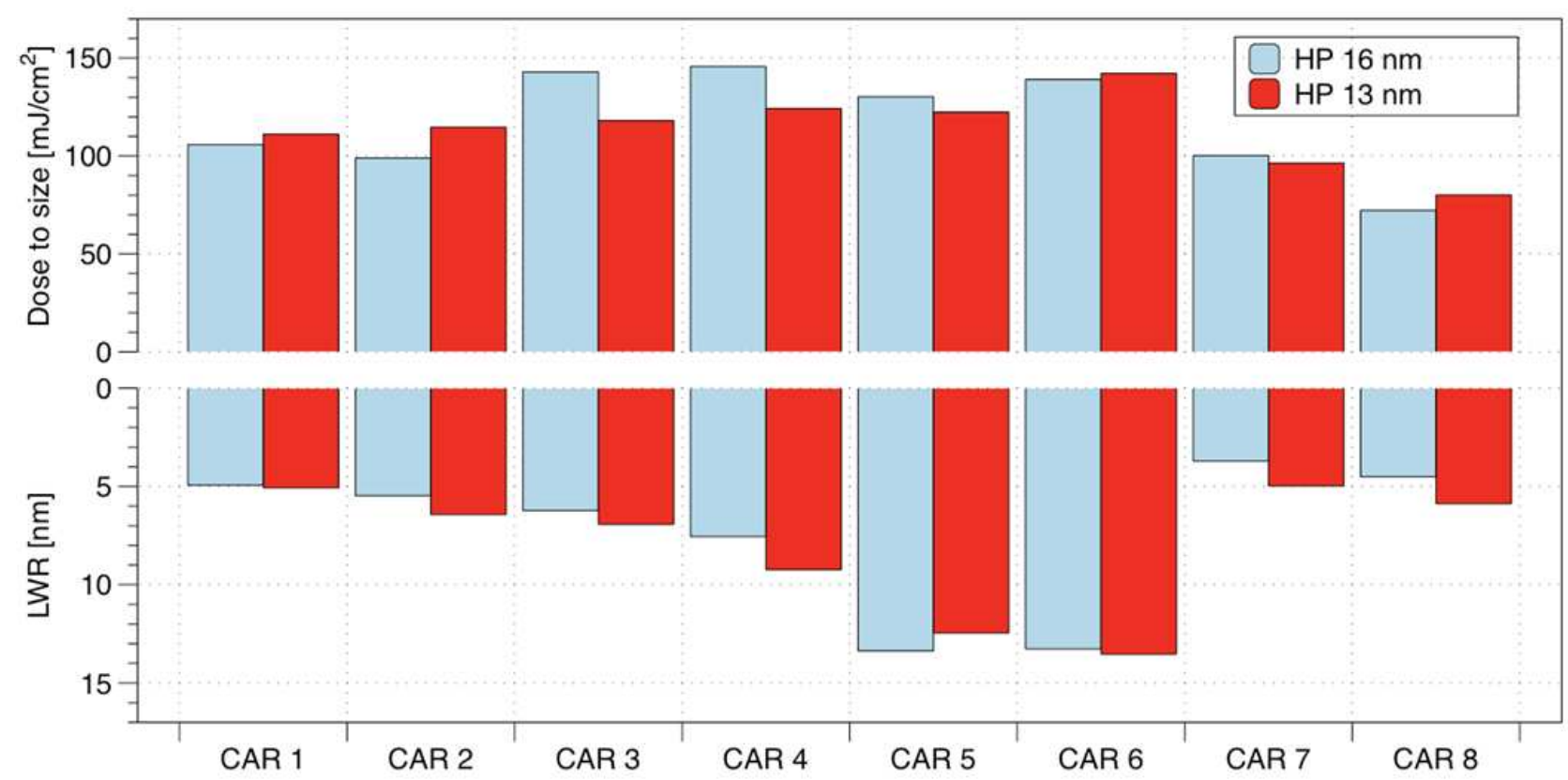

Figure 12. Overview of the performance metrics of CAR Resists for hp $16 \mathrm{~nm}$ and hp $13 \mathrm{~nm}$

Non-CAR resist platforms have also been under investigation, mainly inorganic resists and molecular resists. In Fig. 13, the results for hp 16 and $\mathrm{hp} 11 \mathrm{~nm}$ are shown. There is not a significant difference in between these three resists, dose is around the range of $60-70 \mathrm{~mJ} / \mathrm{cm}^{2}$ and LWR values are around 3 and $4 \mathrm{~nm}$.

In Fig. 14 are the results from the same set of non-CAR resist, which is molecular resist, for hp 16 and $13 \mathrm{~nm}$. Here, dose is less than $50 \mathrm{~mJ} / \mathrm{cm}^{2}$ and LWR values are in the 7-9 $\mathrm{nm}$ range.

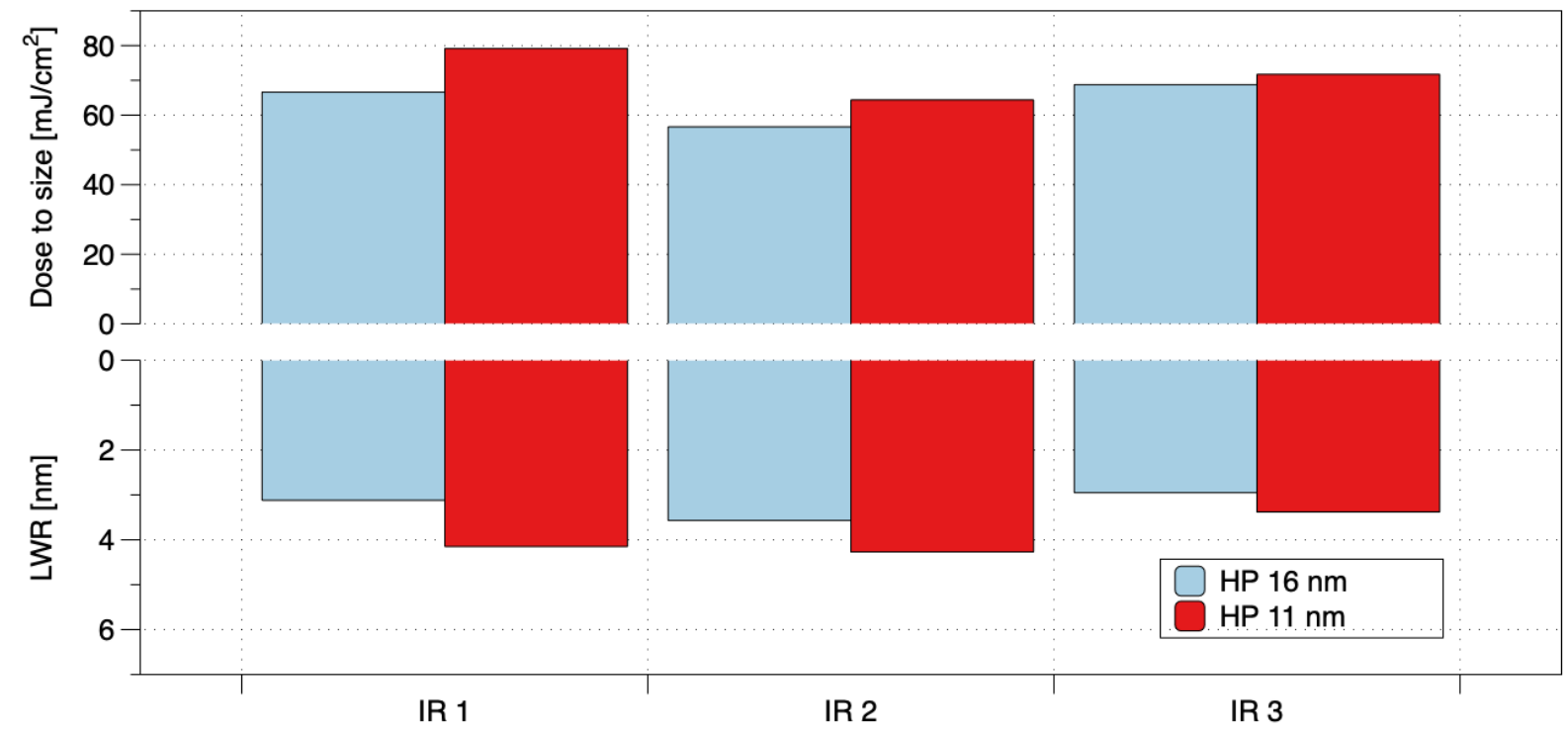

Figure 13. Comparison of the performance of the inorganic EUV resists at hp $16 \mathrm{~nm}$ and hp $11 \mathrm{~nm}$. 


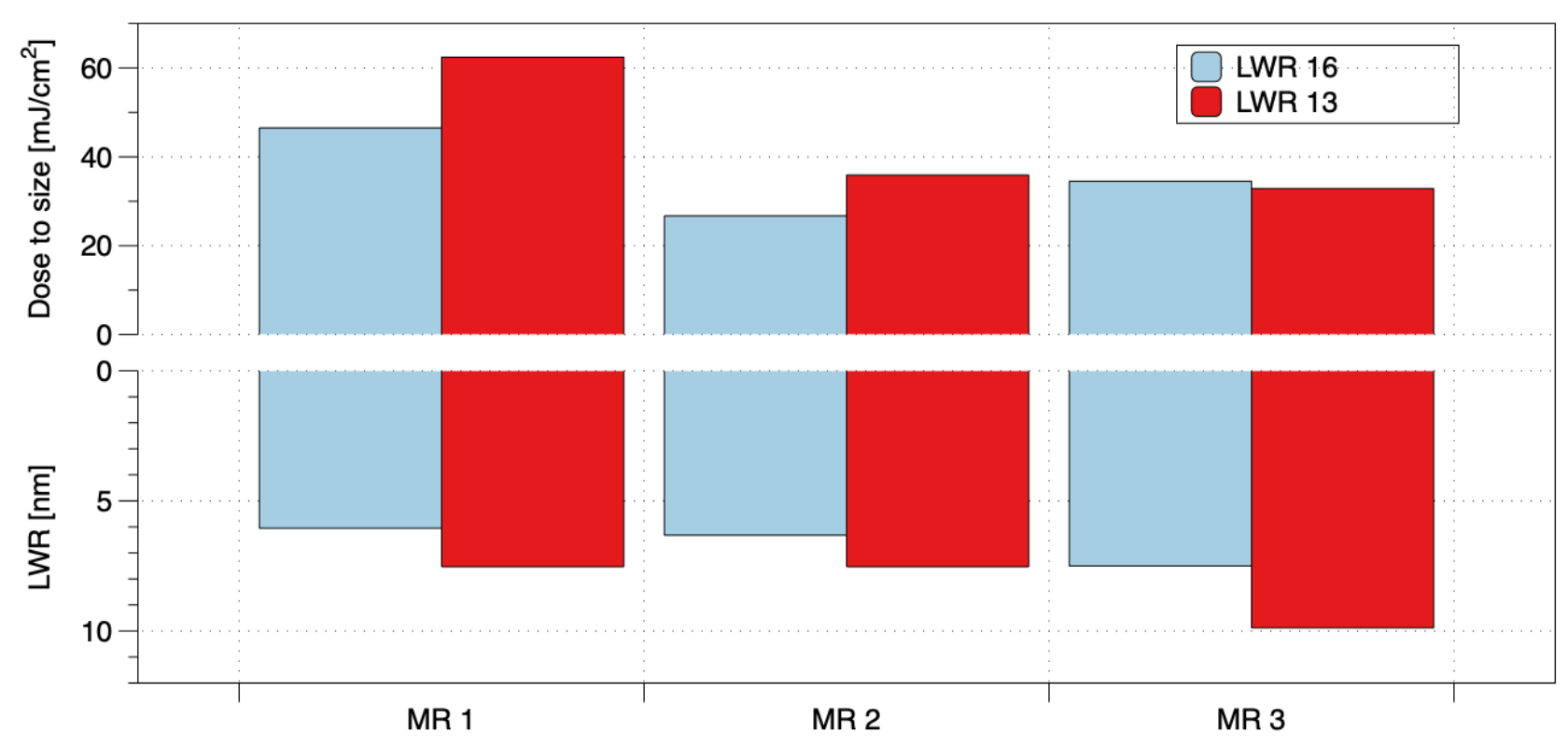

Figure 14. Molecular Resist for hp $16 \mathrm{~nm}$ and hp $13 \mathrm{~nm}$.

\section{CONCLUSIONS}

We established a program which constantly monitors and gets a snapshot of the state-of-the-art EUV resists using the EUV- IL platform at PSI. While, up to now, CARs performance reached down to $13 \mathrm{~nm}$ hp only, we reported about a recent CAR that can partially resolve lines down to $11 \mathrm{~nm} \mathrm{hp}$. Moreover, some other non-CAR resists have achieved resolutions down to $10 \mathrm{~nm}$. We also reported some recent results from new rinse materials which showed improvement of BE and LWR values down to hp 13nm. Also, we have seen some new molecular resist results resolving down to hp 13 $\mathrm{nm}$ with a dose less than $50 \mathrm{~mJ} / \mathrm{cm}^{2}$ and down to hp $12 \mathrm{~nm}$ with certain defects and LWR values around $8 \mathrm{~nm}$. Lastly, we have seen that newly developed inorganic resist can resolve down to $\mathrm{hp} 10 \mathrm{~nm}$ but a relatively higher dose of $70 \mathrm{~mJ} / \mathrm{cm}^{2}$.

\section{REFERENCES}

[1] J. van Schoot et al., "EUV high-NA scanner and mask optimization for sub-8nm resolution," 2016, p. 97761I.

[2] J. van Schoot et al., "High-NA EUV lithography enabling Moore's law in the next decade," in International Conference on Extreme Ultraviolet Lithography 2017, 2017, p. 30.

[3] J. van Schoot et al., "High-numerical aperture extreme ultraviolet scanner for 8-nm lithography and beyond," J. Micro/Nanolithography, MEMS, MOEMS, vol. 16, no. 04, p. 1, Oct. 2017.

[4] D. Fan and Y. Ekinci, "Photolithography reaches $6 \mathrm{~nm}$ half-pitch using EUV light," 2016, p. $97761 \mathrm{~V}$.

[5] E. Buitrago et al., "State-of-the-art EUV materials and processes for the 7nm node and beyond," 2017, p. 101430T.

[6] Z. Tasdemir et al., "Chemically-amplified EUV resists approaching $11 \mathrm{~nm}$ half-pitch," Extrem. Ultrav. Lithogr. IX, p. 66, Mar. 2018.

[7] N. Mojarad, J. Gobrecht, and Y. Ekinci, "Interference lithography at EUV and soft X-ray wavelengths: Principles, methods, and applications," Microelectron. Eng., vol. 143, pp. 55-63, Aug. 2015.

[8] B. Päivänranta, A. Langner, E. Kirk, C. David, and Y. Ekinci, "Sub-10 nm patterning using EUV interference lithography," Nanotechnology, vol. 22, no. 37, p. 375302, Sep. 2011.

[9] N. Mojarad, J. Gobrecht, and Y. Ekinci, "Interference lithography at EUV and soft X-ray wavelengths: Principles, methods, and applications," Microelectron. Eng., vol. 143, pp. 55-63, Aug. 2015.

[10] Z. Tasdemir et al., "Contrast matching of line gratings obtained with NXE3XXX and EUVinterference lithography," in Proceedings of SPIE - The International Society for Optical Engineering, 2017, vol. 10450, p. 65. 